\title{
150 years since the birth of Harvey Williams Cushing
}

\author{
H. Ples ${ }^{1}$, H. Berceanu ${ }^{2}$ \\ 1 "Victor Babes" University of Medicine and Pharmacy, Timisoara, \\ ROMANIA \\ 2 Elias Emergency University Hospital, Bucharest, ROMANIA
}

The first practitioner physicians of modern neurosurgery are Sir William Macewen, (1848-1939) with 21 surgical interventions, and Sir Victor Horsley (1857-1916) who performed 10 skull surgeries in 1886. (1)

During this time, the most important character in the development of neurosurgery was Harvey Cushing. The complex personality of Harvey Cushing becomes evident after reading the monumental biography written by John Fulton. Cushing was a genius with exemplary determination, working strength and an extraordinary perseverance. Like any genius, he was a difficult person, hard to collaborate with. These difficulties were minor in the light of his great achievements. (2)

It seems a sacrilege to criticize a human being who almost by himself abolished the terrible spectre of the "cerebral fungus" which was the common result of surgeries performed in that era.

Harvey Williams was born on April 8, 1869, in Cleveland, Ohio, and died on October 7, 1939 in New Haven, Connecticut. Between 1887 and 1891 he studied at Yale College, and continued his studies and graduated from the Harvard Medical School in 1895 cum laude. He studied for four years at Johns Hopkins Hospital in Baltimore under the famous surgeon W.S. Halsted. (1)

His collaboration with Halsted influenced Cushing's career. Halsted used local anaesthesia with cocaine in the vicinity of nerves. After he injected his own hand, he developed a cocaine addiction, which kept him away from his patients and the operating room. This allowed young Cushing to take on responsibilities closer to those of a senior surgeon, helping him advance in his career. (7)

Harvey Cushing also trained brain surgery techniques with Theodor Kocher in Bern and Charles Scott Sherrington in Liverpool. During his collaboration with Kocher, the "Cushing reflex" was described, which highlighted the relationship between blood pressure and intracranial pressure. He also studied intracranial pressure with Kocher. Together with Sherrington he had contributions to the cortical localization of brain centres (10).

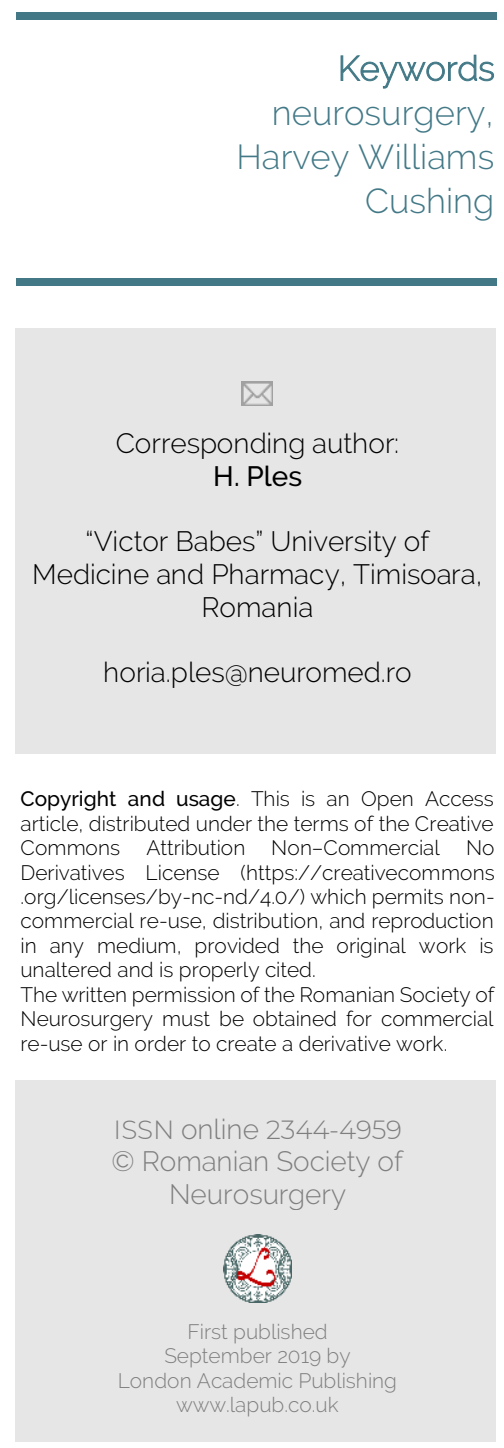


Cushing's best friend was Osler, the famous father of American internal medicine, and one of four professors who founded the Johns Hopkins Hospital. Cushing won the Pulitzer Prize in 1926 with his book "Life of Sir William Osler". He was a surgeon in the same hospital from 1902 to 1912. (3) In 1903 he obtained the title of Associate Professor in surgery. (6) Cushing managed neurological cases. In 1904 he presented "The Special Field of Neurological Surgery" with a great amount of enthusiasm in front of the Medical Academy in Cleveland. (1)

He became chief surgeon at Peter Bent Brigham Hospital in Boston and professor of surgery at Harvard Medical School. Cushing joined Yale in 1933. (3)

Cushing came from two generations of physicians. He married his childhood sweetheart, Katharine S. Crowell, on June 10, 1902 in Cleveland, Ohio. They had five children: two boys and three girls. One of his daughters married James Roosevelt, the son of the president of the United States in that time (Franklin D. Roosevelt). (4)

In his professional life Cushing was a "tough hombre". Nurses were sometimes reduced to tears and residents had nervous breakdowns due to Cushing's withering scorn and sarcasm. He demanded of his team work 98 hours per week. This took a toll on his wife and children. (5) One can see Cushing's character in how he behaved upon the death of his eldest son in a car accident at the age of

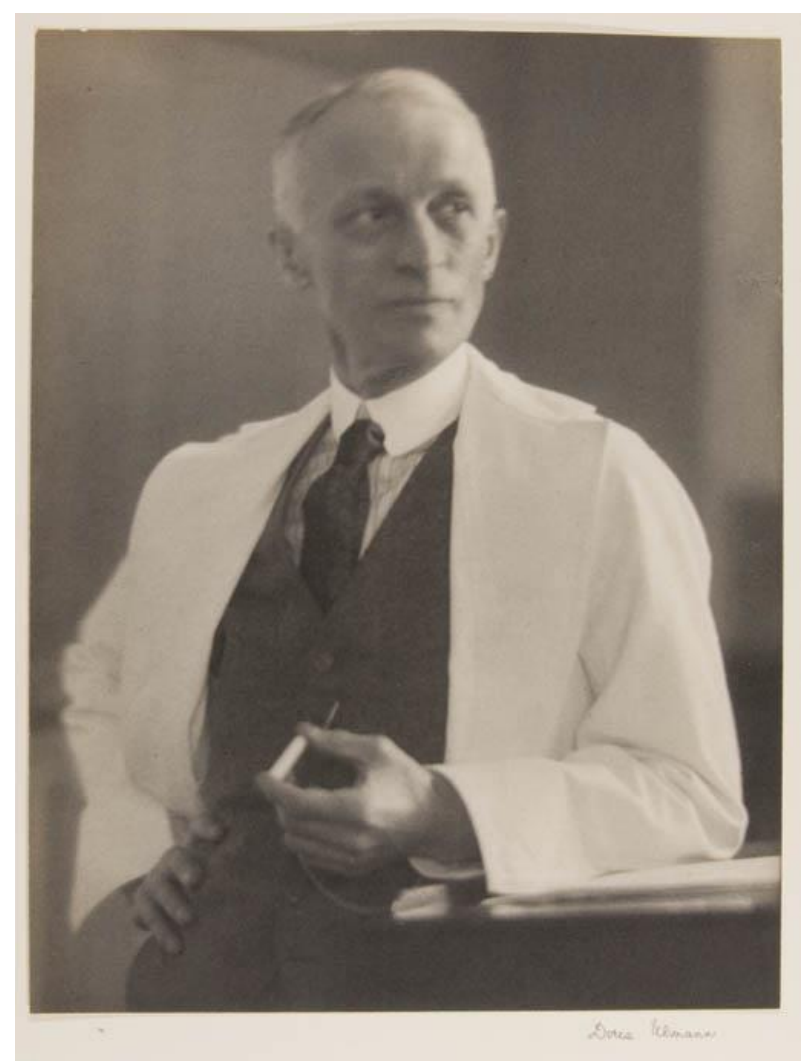

22. He received the news early in the morning. He notified his wife, and then he went to the hospital to perform scheduled surgeries. (1) He smoked a lot, drank very little, did not approve of alcohol in the family, disapproved of jazz, movies, fashion, telephones, friends, women in medicine, women

\section{Harvey Cushing (Boston)}

Thierry de Martel (Paris) Paul Martin (Brussels) Daniel Petit-Dutaillis (Paris) Tracy Putnam (Boston) Jean Morelle (Louvain) John Fulton (New Haven) William Welch (Baltimore) Richard Meagher (Boston) Francis Grant (Philadelphia) Norman Dott (Edinburgh) Frank Fremont-Smith (Boston) Frédéric Bremer (Brussels) Sir Charles Sherrington (Oxford)
Dimitri Bagdazar (Bucharest) Percival Bailey (Chicago) Georges Schaltenbrand (Hamburg) Frederic Schreiber (Detroit) Richard Light (Boston) Herbert Olivecrona (Stockholm) Arnold Klebs (Nyon) Hugh Cairns (London) Ignaz Oljenick (Amsterdam) George Armitage (Leeds) Gaston DeCoppet (Berne) Franc Ingraham (Boston) Geoffrey Jefferson (Manchester) Otfrid Foerster (Breslau)

Wilder Penfield (Montreal) 
smoking, and young men who did not attend classes. (5)

His patients knew another Cushing - wonderful and elegant manners, absolute dedication and empathy. (5)

He was of medium height, elegant, with a depressing smile and pleasant manners. He had charm and charisma, and he was proud of his own attire. He was a good speaker, but a terrible listener, with a tendency to interrogate his interlocutor. He used to follow his scientific ideas even if it meant sacrificing his friends (an example of this is Walter Dandy). His lack of diplomacy sometimes got him in serious trouble, such as the episode in 1917 in France when he was enrolled in the United States Army. Only the intervention of General Pershing saved him from court martial, following an incident that was rather a stupid verbal exchange. (2) After this episode, between 1917-1919, he was the director of the "US Army Base Hospital No 5". (6)

\section{PROFESSIONAL ACTIVITY}

When he entered neurosurgery, postoperative mortality was about $50 \%$. His ability and surgical technique were able to decrease it to $10 \%$. As mentioned above, he spearheaded the eradication of "cerebral fungus". (4)

Cushing's major interest was brain tumours. Between 1912 and 1938 he published 5 books, and he had a database of 2023 brain tumours. (7) In 1931, in Bern, at the first International Neurology Congress (August 31st - September 3rd), Harvey Cushing presented his memorable paper on 2000 brain tumour surgeries, a presentation which remained famous among neurologists and neurosurgeons. In the room there also were 25 of his pupils and at least 1,000 listeners. (7) During the presentation, no one remained outside the meeting room, says John Fulton. During this congress, Harvey Cushing organized a dinner to which he invited the great personalities who were there. The seating arrangement was personally guided by Harvey Cushing. From the image you can see that our countryman Dumitru Bagdasar was placed on the left of the great Cushing; this shows the appreciation and friendship felt by the American neurosurgeon for him.

Dr. Dumitru Bagdasar, subsequently university professor and minister of health in Romania (?)(19451946), specialised in neurosurgery at Peter Bent
Brigham Hospital from 1927-1929 with his mentors Harvey Cushing and Percival Bailey. Prof. A. V. Ciurea (Bucharest) together with Dr. Pleș Horia (Timisoara) visited the Boston hospital. Two articles written by Dumitru Bagdasar during his work in the United States (Treatment of brain gummas and intracranial chordoblastomas) can be found up to this day.

There are several letters addressed by Harvey Cushing to the Romanian neurosurgeon mentioned in Dr. Dumitru Bagdasar's "Work and character" ("Muncă și caracter"). Cushing's affection for doctor Bagdasar is evident from these letters. Here is one of the letters:

\section{Dear Bagdasar,}

I wonder if I have answered you regarding the receiving of the delicious book that you have sent me on the art of Romanian peasants. If I did not, it was an omission. We liked it very much.

I hope that you and your wife are making satisfying progress. We are often talking about you here. I have seen your countryman researcher, Grigore Popa, in London, at the University College. He made an excellent paper on the circulation of the pituitary gland and hypothalamus.

With warm regards, I remain forever yours,

\section{Harvey Cushing}

Together with Louise Eisenhardt, he wrote a monography about brain meningiomas, another passion of Professor Cushing.

The most famous meningioma patient of Cushing was General Leonard Wood, from the US Army. General Wood was chief of military personnel in the USA, himself a military surgeon. In 1899 the General suffered a craniocerebral trauma, apparently without consequences until 1902, when he developed paresthesia in the left lower limb, and then epilepsy. In 1905 he underwent a surgery to remove a tumour mass located at the calvaria and an epidural tumour section. The Jacksonian seizures continued. In 1910, Professor Cushing performed surgery in two steps four days apart to remove an intracranial parasagittal meningioma. General Wood had a complete recovery. No doubt that the General's personal fame helped Cushing to obtain the position of chief surgeon in the new Peter Bent Brigham hospital. In 1927 General Wood came again to Doctor Cushing, this time in Boston, with spastic 
left hemiparesis and ipsilateral hemianopsia. Cushing re-operated the tumour relapse without apparent complications, but the General died unexpectedly a few hours later as a result of a haemorrhage with intraventricular effraction. Cushing commented later: "I was never so upset because of the death of a patient. He was so close to success. He was a great man." (8)

Between 1896-1912 he performed almost 200 surgeries intervention on children, attempting to establish paediatric neurosurgery as a sub-specialty (9).

Cushing studied the pituitary gland (1912), adding to his international reputation. He was the first person who described pituitary gland disorders, now called 'Cushing syndrome' or 'disease'. (3) He was the first person who associated pituitary adenoma with Cushing syndrome.

He used the transsphenoidal approach in 227 patients with a mortality of $5.2 \%$. (4)

One of Cushing's important contributions is in the area of neuroradiology. He immediately understood the importance of Professor Roentgen's discovery, and he managed to bring a Crooke tube to the Massachusetts General Hospital to generate X-rays at approximately five months after the discovery. After he insisted that the Boston hospital have a radiology service. After a few months Cushing left with the tube to the Johns Hopkins Hospital, to the bewilderment of his colleagues. (4)

In November 1896 he used X-rays to investigate a spine after a gunshot. The female patient had Brown-Secquard syndrome. It was for the first time that a neurologic syndrome to benefit of this investigation. The exposure lasted 35 minutes. Cushing was not the first person to appreciate Xrays. In 1987 alone, more than 1,000 articles were published on their role in medicine. (4)

Together with Ernest Amory Codeman, he developed the predecessor of the modern anaesthesia machine, monitoring temperature, heart rate, and blood pressure during surgical interventions. (4)

Among other innovations initiated by Cushing are cortical stimulation, understanding of the natural evolution of the central nervous system, and understanding of increases in intracranial pressure. He collaborated with W.T. Bovie in the development of the electrocautery with the same name, leading in
1925 to the resection of a brain tumour, and to widescale use since 1928. (4)

Cushing's scientific activities included those of his resident, Walter E. Dandy, with whom he worked on hydrocephaly. Dandy discovered ventriculography, but Cushing was upset that he experimented on children with hydrocephaly and not on dogs, as there was a risk of secondary herniation of the amygdalae. (4) On the other hand Dandy did not agree with Cushing on using metallic clamps in aneurysm surgery. (4)

The relationship between Cushing and Dandy was tense, as Dandy was quite aggressive. (4)

When they are talking about the competition between Harvey Cushing and Walter Dandy, other authors think that the first did not have an elegant behaviour. (7)

When the composer George Gershwin was discovered with a brain tumour and went into a coma, Cushing was sought immediately. As he retired several years before, he recommended Dr. Walter Dandy, who was on the ocean with the governor of the state of Maryland. The White House sent a Coast Guard ship to fetch Dandy as quick as possible.

He published 13 books and over 300 articles during his career. The best known books are "Surgery of the Head" (1910), "The Pituitary Body and its Disorders" (1912), and "Meningiomas" (1938).

At Cushing's suggestion in 1919, the "Society of Neurological Surgery" was formed, and in 1931, with Cushing's permission, a group of young neurosurgeons founded the "Harvey Cushing Society". (1)

He donated his collection of books and magazines to the Yale Medical Library near the end of his career. (1)

The destroyer "USS Cushing", named to honour the achievements of Harvey Cushing, was launched on December 31, 1935. In 1988 he was honoured with a stamp issued as part of the "Great Americans" series. (1)

NOTES

1. L. F. Haas. (2002). Neurological Stamp. Journal of Neurology, Neurosurgery, and Psychiatry, p. 596, http://dx.doi.org/ 10.1136/jnnp.73.5.596.

2. Derek Denny - Brown. (1979). Harvey Cushing: The Man, Journal of Neurosurgery, Vol. 50, Ian. 1979, DOI: 10.3171/jns.1979.50.1.0017. 
3. https://www.britannica.com/biography/Harvey-WilliamsCushing.

4. Richard B. Gunderman and Zachary A. Seymour. (2010). 'Harvey Cushing', American Journal of Roentgenology. 2010; 194: 296-298. 10.2214/AJR.09.3356.

5. Peter Farley. (2006). Harvey Cushing: the man, the surgeon and the father, Yale Medicine, 2006, https://medicine .yale.edu/news/yale-medicine-magazine/ harvey-cushingthe-man-the-surgeon-and-the.aspx

6. John F. Fulton. (1946). Harvey Cushing-a Biography. By. Pp. 754. Oxford: Blackwell
7. Michael Bliss. Harvey Cushing: A Life in Surgery, Oxford University Press, ISBN-13: 978-0195329612

8. Joung $H$. Lee. Meningiomas, Springer, ISBN 978-1-84628526-4, DOI: 10.1007/978-1-84628-784-8

9. Vivek A. Mehta, Olindi Wijesekera, Courtney Pendleton, Alfredo Quiñones-Hinojosa, George I. Jallo and Edward S. Ahn. Harvey Cushing and "birth haemorrhage": early paediatric neurosurgery at The Johns Hopkins Hospital. Historical vignette, DOI: https://doi.org/10.3171/2011. 9.PEDS11198

10. Chisholm Hugh. (1922). "Cushing, Harvey" . Encyclopcedia Britannica (12th ed.). London \& New York. 